\title{
Risk factors for delay in symptomatic presentation: a survey of cancer patients
}

\author{
L J L Forbes ${ }^{*}$, , F Warburton ${ }^{1}$, M A Richards ${ }^{2,3}$ and A J Ramirez ${ }^{1}$ \\ ${ }^{1}$ King's College London Promoting Early Cancer Presentation Group, Capital House, 42 Weston Street, London SE1 3QD, UK and \\ ${ }^{2}$ At the time of completing this research: National Cancer Action Team, Portland House, Bressenden Place, London SW1E 5RS, UK
}

Background: Delay in symptomatic presentation leading to advanced stage at diagnosis may contribute to poor cancer survival. To inform public health approaches to promoting early symptomatic presentation, we aimed to identify risk factors for delay in presentation across several cancers.

Methods: We surveyed 2371 patients with 15 cancers about nature and duration of symptoms using a postal questionnaire. We calculated relative risks for delay in presentation (time from symptom onset to first presentation $>3$ months) by cancer, symptoms leading to diagnosis and reasons for putting off going to the doctor, controlling for age, sex and deprivation group.

Results: Among 1999 cancer patients reporting symptoms, 21\% delayed presentation for $>3$ months. Delay was associated with greater socioeconomic deprivation but not age or sex. Patients with prostate $(44 \%)$ and rectal cancer $(37 \%)$ were most likely to delay and patients with breast cancer least likely to delay (8\%). Urinary difficulties, change of bowel habit, systemic symptoms (fatigue, weight loss and loss of appetite) and skin symptoms were all common and associated with delay. Overall, patients with bleeding symptoms were no more likely to delay presentation than patients who did not have bleeding symptoms. However, within the group of patients with bleeding symptoms, there were significant differences in risk of delay by source of bleeding: $35 \%$ of patients with rectal bleeding delayed presentation, but only $9 \%$ of patients with urinary bleeding. A lump was a common symptom but not associated with delay in presentation. Twenty-eight percent had not recognised their symptoms as serious and this was associated with a doubling in risk of delay. Embarrassment, worry about what the doctor might find, being too busy to go to the doctor and worry about wasting the doctor's time were also strong risk factors for delay, but were much less commonly reported $(<6 \%)$.

Interpretation: Approaches to promote early presentation should aim to increase awareness of the significance of cancer symptoms and should be designed to work for people of the lowest socioeconomic status. In particular, awareness that rectal bleeding is a possible symptom of cancer should be raised.

Inequalities in cancer survival may be explained by differences in tumour biology, access to effective treatment and stage at diagnosis. Delay in presentation with symptoms among patients with cancer is likely to contribute to late stage at diagnosis and, thereby, poorer survival (Richards et al, 1999; Neal, 2009; De Angelis et al, 2014).

How long a cancer patient takes to present may be influenced by several factors, including the nature of the symptoms, awareness of the significance of the symptoms, perception of personal risk of cancer, and physical, social and psychological barriers to health care (Ramirez et al, 1999; Macleod et al, 2009). In the UK, awareness in the general population that the risk of cancer increases with age is low and reporting that embarrassment and worry about wasting the doctor's time might put them off going to the doctor is common compared with similar countries (Forbes et al, 2013). However, we do not yet have evidence to explain fully

${ }^{*}$ Correspondence: Dr LJL Forbes; E-mail: lindsay.forbes@kcl.ac.uk

${ }^{3}$ Current address: Care Quality Commission, Finsbury Tower, 103-105 Bunhill Row, London, EC1Y 8TG, UK.

Received 24 January 2014; revised 2 May 2014; accepted 11 May 2014; published online 10 June 2014

(c) 2014 Cancer Research UK. All rights reserved 0007-0920/14 
why some cancer patients delay symptomatic presentation. This evidence is important to inform interventions to promote early presentation (Austoker et al, 2009).

Approaches to promoting early presentation generally focus on specific cancers (Austoker et al, 2009; Athey et al, 2011; Forbes et al, 2011). However, when a patient experiences symptoms, they may not associate these with the possibility of a specific cancer and seek help, even if they have been exposed to a campaign particularly if their symptoms are not specific for cancer, for example, weight loss or abdominal pain. Campaigns to promote early symptomatic presentation of cancer may have more impact on mortality if they address the risk factors for delay in presentation in general.

We aimed to identify risk factors for the delay in presentation by socio-demographic characteristics, cancer type, symptom type and reported reasons for not going to the doctor across a population of cancer patients, to inform the development of public health approaches to promote early presentation.

\section{MATERIALS AND METHODS}

Sampling. Cancer patients were selected from people who had taken part in the English Department of Health's Cancer Patient Experience Survey in mid-2010 (Department of Health, 2010). This included all adult cancer patients who had received treatment at 1 of 158 National Health Service (NHS) hospitals in England from January-March 2010. These patients had been sent a postal questionnaire asking about their experiences of health care, and 67713 patients responded (66\%).

Of the respondents, 53104 agreed that they could be recontacted for further surveys. We identified who among these had died using the national Demographic Batch Service system (Health and Social Care Information Centre, 2014), which maintains an up-to-date list of all NHS patients. We randomly sampled 200 patients, each with 1 of 22 cancer types (Table 1 provides International Classification of Diseases codes), from those alive in November 2011. Only 181 patients with pancreatic cancer were alive in November 2011, so we sent a questionnaire to all of them. The cancer types were selected to include common cancers and some rarer cancers for which we had identified a lack of information about nature and duration of symptoms. We aimed for a sample size of 3000 for patients with 1 of all 22 cancer types, which would provide reasonable precision around estimates of frequency of symptoms for the entire population of cancer patients.

For the analysis described in this paper, we included only patients with 1 of 15 cancers where $>75 \%$ patients who had taken part in the Cancer Patient Experience Survey 2010 were still alive in November 2011 (Table 1). This was to minimise 'survivor' bias introduced by surveying only those who were alive at least 16 months after the Cancer Patient Experience survey. Cancers included in the analysis were cancers of breast, colon, rectum, cervix, endometrium, oral cavity, kidney/ureter, bladder and prostate; malignant melanoma; sarcoma; chronic myeloid leukaemia, chronic lymphocytic leukaemia, non-Hodgkin's lymphoma, and myeloma. These 15 cancer types represent $61 \%$ of the population of cancer patients in England (excluding nonmelanoma skin cancer) (Office for National Statistics, 2011). The most common cancers that we excluded from the analysis were lung and upper gastrointestinal cancers.

The questionnaire. The patients were sent a self-complete questionnaire asking about the nature of the symptoms that had caused them to see a doctor and led to diagnosis. Patients were asked to identify symptoms from a list, because this type of data could be analysed more reliably than responses to open questions. Participants could tick more than one symptom. We developed
Table 1. Proportions of patients alive in November 2011, of those who took part in the National Cancer Patient Experience Survey 2010, and response to the survey among those sampled

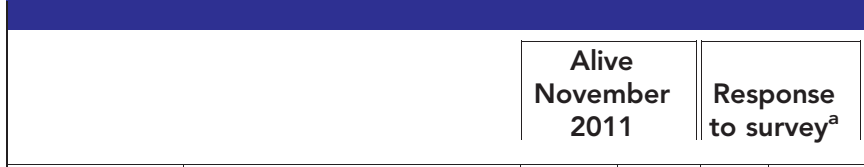

\begin{tabular}{|l|l|l|l|l|l|}
\hline ICD-10 & Cancer type & $n$ & (\%) & $n$ & (\%) \\
\hline
\end{tabular}

Included in the analysis of risk factors for delay in presentation

\begin{tabular}{|l|l|r|r|r|l}
\hline C43 & Malignant melanoma & 963 & $(92.3)$ & 159 & $(79.9)$ \\
C50 & Breast (women) & 10,078 & $(91.1)$ & 164 & $(82.4)$ \\
C67 & Bladder & 4,637 & $(89.6)$ & 160 & $(80.4)$ \\
C92.1 & Chronic myeloid leukaemia & 218 & $(89.3)$ & 159 & $(79.5)$ \\
C54 & Body of uterus & 865 & $(87.6)$ & 158 & $(79.4)$ \\
C82-83 & Non-Hodgkin's lymphoma & 1,730 & $(87.5)$ & 161 & $(80.9)$ \\
C53 & Cervix & 287 & $(85.2)$ & 133 & $(67.2)$ \\
C61 & Prostate & 3,489 & $(84.1)$ & 170 & $(85.0)$ \\
C91.1 & Chronic lymphocytic leukaemia & 700 & $(82.1)$ & 161 & $(80.5)$ \\
C64-66 & Kidney and ureter & 702 & $(82.0)$ & 154 & $(78.6)$ \\
C19-20 & Rectum & 2,195 & $(81.4)$ & 175 & $(88.4)$ \\
C18 & Colon & 3,039 & $(80.0)$ & 166 & $(84.3)$ \\
C40-41, C49 & Sarcoma & 280 & $(78.9)$ & 140 & $(70.7)$ \\
C90 & Myeloma & 1,695 & $(78.8)$ & 150 & $(76.1)$ \\
C01-06 & Oral cavity & 370 & $(77.4)$ & 161 & $(81.7)$ \\
\end{tabular}

Not included in the analysis of risk factors for delay in presentation

\begin{tabular}{|l|l|r|r|r|l|}
\hline C91.0, C92.0 & Acute leukaemia & 477 & $(68.1)$ & 154 & $(80.2)$ \\
C56 & Ovary & 927 & $(65.3)$ & 152 & $(77.2)$ \\
C77-79 & Secondary cancer & 1,959 & $(60.4)$ & 144 & $(74.6)$ \\
C16 & Stomach & 425 & $(55.7)$ & 140 & $(73.7)$ \\
C15 & Oesophagus & 533 & $(50.5)$ & 155 & $(81.2)$ \\
C34 & Lung & 1,230 & $(48.3)$ & 142 & $(77.2)$ \\
C25 & Pancreas & 181 & $(38.9)$ & 113 & $(71.5)$ \\
\hline
\end{tabular}

${ }^{a} \mathrm{~A}$ further 88 patients died during fieldwork; these have been removed from the denominator in calculating response rates.

cancer-specific versions of the questionnaire (shown in Supplementary Material), so as to keep the list of symptoms short. The symptom lists were developed with the input of clinical experts in the relevant cancers.

The questionnaire asked participants how long it was from noticing the symptom that led to diagnosis to presenting to a doctor ( $<2$ weeks $/ 2-4$ weeks $/>4$ weeks to 3 months $/>3$ months to 6 months/>6 months to 12 months/ $>1$ year), the date the presenting symptom started and date of first going to a doctor. The questionnaire asked what had put the patient off seeing a doctor (based on those in the validated Awareness and Beliefs about Cancer measure (Simon et al, 2012) and Cancer Research UK Cancer Awareness Measure (Stubbings et al, 2009)).

Questionnaires for breast, bowel and cervical cancer also asked about whether the patient had been diagnosed via a NHS Cancer Screening Programme.

The questionnaire was based on our previous studies of breast and cervical cancer (Burgess et al, 1998; Lim et al, 2013). The questionnaires were piloted and cognitively tested (Campanelli, 1997) in three rounds. This aimed to ensure that the questions were easy to complete, acceptable and understandable, and to test the ability of patients to recall events. The patients, recruited through Macmillan Cancer Support, were first sent the questionnaires. Trained interviewers then conducted telephone interviews, asking the patients to describe in their own words what they thought the questions were asking, and 'think aloud' to describe how they would answer. 
Data collection. A postal survey was carried out between November 2011 and January 2012. We sent two reminders to non-responders.

Statistical analysis. We excluded all patients who reported being diagnosed via a screening programme (i.e., breast, bowel, cervix) or who reported no symptoms. We assigned each patient an Index of Multiple Deprivation (IMD) based on postcode (Public Health Observatory, 2011). The IMD provides a measure of socioeconomic deprivation based on the characteristics of the area of residence of each individual (Department for Communities and Local Government, 2014), a higher score indicating greater deprivation. We categorised people into quintiles of IMD in England.

We categorised symptoms into nine categories (or 'other) (Supplementary Box S1, online supplement), to reflect a patient's experience rather than the pathology underlying the symptoms. We coded free text symptoms into these categories where possible.

We weighted the percentages reporting each symptom for the incidence of the cancer (using 2009 national cancer registration data (Office for National Statistics, 2011) to give percentages more representative of the whole population of cancer patients.

We calculated duration of symptoms leading to diagnosis based on the response to the question: 'In these first few questions we would like to know about the MAIN health problems or symptoms that made you go to see the GP (family doctor), or made you go to accident and emergency, and that led to you being diagnosed with cancer.... How long was it from the time you noticed these MAIN health problems or symptoms and first seeing a GP or hospital doctor?' (Questionnaires provided in Supplementary Material). Where patients had not responded to the question about duration of symptoms, we calculated duration from dates provided by the patient, if they had given day, month and year for both onset of symptoms and date of seeing a doctor. We considered $>3$ months from onset of symptoms to presentation as a 'delay', as this is conventional and likely to represent a clinically important delay (Richards et al, 1999).

We calculated relative risks for delay in presentation, fitting log-binomial regression models using the Stata command $\mathrm{glm}$, by cancer, presenting symptom and reasons for putting off going to the doctor. We controlled for age, sex and deprivation group, because we judged in advance that these might influence time to presentation (Ramirez et al, 1999; Macleod et al, 2009).

As a survey of perceptions of NHS patient care designed to improve services, no formal ethics approval was sought for the Cancer Patient Experience Survey by the Department of Health. However, all patients approached, as part of our survey had given written consent to being recontacted.

\section{RESULTS}

Completeness of sample. In late 2011, the proportion of those who took part in the Cancer Patient Experience Survey 2010 who were alive at the time of our survey varied by cancer (Table 1 ), from $92 \%$ in malignant melanoma to $77 \%$ for cancer of the oral cavity.

Response. We sent questionnaires to 4381 patients. These included 3000 patients with 1 of the 15 cancer types selected for this analysis. We received completed questionnaires from 2371 (79\%) of these patients. Response varied by cancer, from $67 \%$ (cervix cancer) to $88 \%$ (rectal cancer) (Table 1).

Participants. In total, 1999 patients reported any symptoms and that they had not been diagnosed via an NHS Cancer Screening Programme. All had been diagnosed in the year before the Cancer Patient Experience Survey 2010. Of the patients reporting symptoms, $1077(54 \%)$ were male, $534(27 \%)$ were aged $70+$ and $1539(77 \%)$ were aged $50+$; all were of White ethnic group. In the population of cancer patients registered in England in 2009 with 1 of the 15 cancer types, $51 \%$ were male, $47 \%$ were aged $70+$ and $89 \%$ were aged $50+$ (Office for National Statistics, 2011). Median IMD was 13.8 (English median is 15) (Public Health Observatory, 2011).

What were the symptoms that led to a diagnosis of cancer? Table 2 shows the proportions of patients with each cancer type reporting each type of symptom. There were relatively few women with breast or cervical cancer because many of these reported that they had been diagnosed by NHS Cancer Screening Programmes.

Table 2 also shows the frequency of symptoms overall and by cancer. The five commonest presenting symptoms were pain (reported by $29 \%)$, lump (28\%), bleeding (23\%), difficulty with urination (18\%) and systemic symptoms (17\%). Among the patients with pain, musculoskeletal pain and abdominal pain were equally common (each reported by $9 \%$ of the total). Rectal bleeding was the commonest type of bleeding (10\%) followed by urinary (8\%) and vaginal bleeding (4\%). The commonest systemic symptom was fatigue $(13 \%)$. Eating-related symptoms and chest symptoms were uncommon, which is likely to be because we excluded patients with upper gastrointestinal and lung cancers.

What put you off going to the doctor? In total, 965 patients (48\%) reported anything that put them off going to the doctor (Table 3), most commonly not realising that the symptom was serious (27\%). Most patients reporting this had common presenting symptoms: $33 \%$ pain, $29 \%$ systemic symptoms, $22 \%$ lump or swelling, and $21 \%$ bleeding. Other reasons for putting off going to the doctor were rarely reported, the most common being worry about wasting the doctor's time, reported by $6 \%$.

How long was it from noticing the symptoms to first seeing a doctor? We had data on duration of symptoms for 1835 patients (92\%). The proportion with these data available varied by cancer, being most complete in non-Hodgkin's lymphoma (96\%) and least complete in chronic leukaemia (86\%) (Supplementary Table S1, Supplementary Material). There was no difference in distribution of sex and IMD between those with and without duration of symptoms data, although data completeness varied slightly by age, being more complete in younger people (aged 70+: 90\%; aged 50-69: 94\%; aged <50: 95\%, $P=<0.01$ ).

In total, $423(21 \%)$ patients reported delay in presentation $(>3$ months from first noticing the symptom to first going to see a doctor).

\section{Risk factors for delay in presentation}

Age, sex and socioeconomic status. There was no difference in frequency of delay by age or sex, although there was a trend suggesting that older people might be less likely to delay (Table 4). The most socioeconomically deprived group was most likely to report delay (29\%).

Cancer type. Patients with prostate (48\%) and rectal cancer (37\%) were most likely to report delay, and were statistically significantly more likely to report delay than patients with chronic lymphocytic leukaemia (chosen as the reference group because the proportion reporting delay was closest to the pooled average) (Table 5). Eight percent of women with breast cancer reported delay and this was the only group statistically significantly less likely to report delay than patients with chronic lymphocytic leukaemia.

Symptom type. The symptoms statistically significantly associated with delay in presentation were difficulties with urination (41\%), change of bowel habit (38\%), skin symptoms (31\%), and systemic symptoms (29\%). There was an association of borderline statistical 


\begin{tabular}{|c|c|c|c|c|c|c|c|c|c|c|}
\hline & & Pain & $\begin{array}{l}\text { Lump/ } \\
\text { swelling }\end{array}$ & Bleeding & $\begin{array}{c}\text { Urinary } \\
\text { difficulties }\end{array}$ & Systemic & $\begin{array}{c}\text { Change of } \\
\text { bowel habit }\end{array}$ & Skin & $\begin{array}{c}\text { Chest } \\
\text { symptoms }\end{array}$ & $\begin{array}{l}\text { Eating- } \\
\text { related }\end{array}$ \\
\hline \multirow[t]{2}{*}{ Most common examples } & $\mathbf{n}$ & $\begin{array}{l}\text { Musculo- } \\
\text { skeletal } \\
\text { Chest } \\
\text { Abdominal }\end{array}$ & $\begin{array}{l}\text { Lump in } \\
\text { breast, } \\
\text { neck, } \\
\text { armpit, } \\
\text { groin, } \\
\text { abdomen }\end{array}$ & $\begin{array}{c}\text { Rectal } \\
\text { bleeding } \\
\text { Haematuria } \\
\text { Vaginal } \\
\text { bleeding }\end{array}$ & $\begin{array}{c}\text { Frequency } \\
\text { Hesitancy } \\
\text { Urgency } \\
\text { Nocturia }\end{array}$ & $\begin{array}{l}\text { Fatigue } \\
\text { Weight } \\
\text { loss } \\
\text { Loss of } \\
\text { appetite }\end{array}$ & $\begin{array}{c}\text { Diarrhoea } \\
\text { Constipation }\end{array}$ & $\begin{array}{l}\text { Mole } \\
\text { Itchiness } \\
\text { Rash or } \\
\text { red spots }\end{array}$ & $\begin{array}{c}\text { Shortness } \\
\text { of breath } \\
\text { Cough }\end{array}$ & $\begin{array}{c}\text { Nausea } \\
\text { Vomiting } \\
\text { Indigestion }\end{array}$ \\
\hline & $n$ & $n(\%)$ & $n(\%)$ & $n(\%)$ & $n(\%)$ & $n(\%)$ & $n(\%)$ & $n(\%)$ & $n(\%)$ & $n(\%)$ \\
\hline \multicolumn{11}{|l|}{ Haemato-oncological } \\
\hline Chronic lymphocytic leukaemia & 122 & $22(18.0)$ & $56(45.9)$ & $4(3.3)$ & $2(1.6)$ & $69(56.6)$ & $2(1.6)$ & $20(16.4)$ & $46(37.7)$ & $1(0.8)$ \\
\hline Chronic myeloid leukaemia & 148 & $67(45.3)$ & $9(6.1)$ & $11(7.4)$ & $1(0.7)$ & $104(70.3)$ & $4(2.7)$ & $31(20.9)$ & $50(33.8)$ & $1(0.7)$ \\
\hline Myeloma & 134 & $88(65.7)$ & $4(3.0)$ & $8(6.0)$ & $1(0.7)$ & $63(47.0)$ & $2(1.5)$ & $13(9.7)$ & $27(20.1)$ & $2(1.5)$ \\
\hline Non-Hodgkin's lymphoma & 157 & $46(29.3)$ & $89(56.7)$ & $2(1.3)$ & $1(0.6)$ & $63(40.1)$ & $7(4.5)$ & $14(8.9)$ & $33(21.0)$ & $2(1.3)$ \\
\hline \multicolumn{11}{|l|}{ Gastrointestinal } \\
\hline Colon & 116 & $49(42.2)$ & $2(1.7)$ & $35(30.2)$ & & $45(38.8)$ & $49(42.2)$ & $1(0.9)$ & $17(14.7)$ & $3(2.6)$ \\
\hline Rectum & 140 & $30(21.4)$ & $1(0.7)$ & $102(72.9)$ & & $29(20.7)$ & $84(60.0)$ & $1(0.7)$ & $4(2.9)$ & \\
\hline \multicolumn{11}{|l|}{ Gynaecological } \\
\hline Uterus & 149 & $31(20.8)$ & $1(0.7)$ & $115(77.2)$ & $2(1.3)$ & $31(20.8)$ & & & $1(0.7)$ & $1(0.7)$ \\
\hline Cervix & 82 & $32(39.0)$ & $1(1.2)$ & $62(75.6)$ & $1(1.2)$ & $20(24.4)$ & $2(2.4)$ & & & \\
\hline \multicolumn{11}{|l|}{ Urogenital } \\
\hline Kidney and ureter & 133 & $54(40.6)$ & $7(5.3)$ & $62(46.6)$ & $22(16.5)$ & $36(27.1)$ & $1(0.8)$ & & $19(14.3)$ & \\
\hline Bladder & 153 & $33(21.6)$ & $2(1.3)$ & $130(85.0)$ & $48(31.4)$ & $15(9.8)$ & & & $3(2.0)$ & \\
\hline Prostate & 133 & $51(38.3)$ & & $13(9.8)$ & $108(81.2)$ & $16(12.0)$ & $2(1.5)$ & & $1(0.8)$ & \\
\hline \multicolumn{11}{|l|}{ Other } \\
\hline Breast & 88 & $18(20.5)$ & $72(81.8)$ & & & $3(3.4)$ & & $12(13.6)$ & & \\
\hline Malignant melanoma & 151 & & $18(11.9)$ & $1(0.7)$ & & & & $133(88.1)$ & $2(1.3)$ & $2(1.3)$ \\
\hline Bone or soft tissue sarcoma & 135 & $26(19.3)$ & $106(78.5)$ & $1(0.7)$ & & $4(3.0)$ & $2(1.5)$ & $2(1.5)$ & $4(3.0)$ & \\
\hline Oral cavity & 158 & $41(25.9)$ & $67(42.4)$ & $1(0.6)$ & & $2(1.3)$ & & & & $17(10.8)$ \\
\hline All & 1999 & $588(29.4)$ & $435(21.8)$ & $547(27.4)$ & $186(9.3)$ & $500(25.0)$ & $155(7.8)$ & $227(11.4)$ & $207(10.4)$ & $29(1.5)$ \\
\hline Weighted percentage ${ }^{a}$ & & 28.5 & 28.0 & 23.0 & 17.6 & 17.0 & 10.9 & 10.3 & 5.3 & 0.8 \\
\hline
\end{tabular}

Table 3. Frequency of reported reasons for putting off going to the doctor (1999 patients reporting at least one symptom)

\begin{tabular}{|l|c|c|}
\cline { 2 - 3 } \multicolumn{2}{|c|}{} & Reported barrier \\
\cline { 2 - 3 } & $\mathbf{n}$ & (\%) \\
\hline I did not realise the symptom was serious & 540 & $(27.0)$ \\
\hline I was worried about wasting the doctor's time & 114 & $(5.7)$ \\
\hline I was worried about what the doctor might find & 75 & $(3.8)$ \\
\hline I was too busy to make time to go to the doctor & 70 & $(3.5)$ \\
\hline It was difficult to make an appointment with the doctor & 48 & $(2.4)$ \\
\hline I was too embarrassed to go to see the doctor & 32 & $(1.6)$ \\
\hline
\end{tabular}

significance between pain and delay in presentation (26\%). Patients reporting lump or swelling were statistically significantly less likely to have delayed than patients not reporting lump or swelling (Table 5).

Symptom type was strongly associated with cancer type. Most patients with urinary difficulties had either prostate or bladder cancer (84\%). Most patients with change of bowel habit (86\%) had cancer of the colon or rectum. Most patients with skin symptoms (91\%) had malignant melanoma or haemato-oncological cancer. This means that it was not possible to identify whether the symptom type itself, or some other feature of the cancer, was causally associated with delay.

Patients with abdominal pain were slightly more likely to report delay (31\%) than those with musculoskeletal pain (25\%). Although bleeding overall was not associated with delay in presentation, the type of bleeding did appear to be important: $35 \%$ of patients with rectal bleeding, $30 \%$ of patients with vaginal bleeding, but only $9 \%$ of patients with urinary bleeding delayed presentation.

Reported reasons for putting off going to the doctor. Patients who reported that they had not realised that the symptom was serious were more likely to delay presentation than patients who did not report this (Table 5). Being too embarrassed to see the doctor, worry about what the doctor might find, worry about wasting the doctor's time and being too busy were all statistically significantly associated with delay in presentation (Table 5). Finding it difficult to make an appointment was not associated with delay in presentation. 


\begin{tabular}{|c|c|c|c|}
\hline \multicolumn{4}{|c|}{$\begin{array}{l}\text { Table 4. Demographic risk factors for delay in presen } \\
\text { with at least one symptom and known duration of } s \\
\qquad \text { Delay in presentation }\end{array}$} \\
\hline & $n$ & (\%) & $\begin{array}{l}\text { Relative risk } \\
\text { for delay in } \\
\text { presentation } \\
(95 \% \mathrm{Cl})\end{array}$ \\
\hline \multicolumn{4}{|l|}{ Age } \\
\hline $\begin{array}{l}<50 \text { (reference) } \\
50-69 \\
70-79 \\
80+\end{array}$ & $\begin{array}{c}71 / 304 \\
217 / 940 \\
85 / 391 \\
16 / 88\end{array}$ & $\begin{array}{l}(23.4) \\
(23.1) \\
(21.7) \\
(18.2)\end{array}$ & $\begin{array}{c}1.00 \\
0.99(0.77-1.25) \\
0.93(0.69-1.22) \\
0.76(0.46-1.24)\end{array}$ \\
\hline \multicolumn{4}{|l|}{ Sex } \\
\hline $\begin{array}{l}\text { Male (reference) } \\
\text { Female }\end{array}$ & $\begin{array}{l}227 / 985 \\
196 / 850\end{array}$ & $\begin{array}{l}(23.0) \\
(23.1)\end{array}$ & $\begin{array}{c}1.00 \\
1.00(0.84-1.18)\end{array}$ \\
\hline \multicolumn{4}{|l|}{ Deprivation group } \\
\hline Least deprived (reference) & $\begin{array}{c}97 / 474 \\
84 / 437 \\
101 / 406 \\
69 / 293 \\
66 / 208\end{array}$ & $\begin{array}{l}(20.5) \\
(19.2) \\
(24.9) \\
(23.5) \\
(28.8)\end{array}$ & $\begin{array}{c}1.00 \\
0.94(0.73-1.20) \\
1.20(0.95-1.49) \\
1.14(0.88-1.45) \\
1.51(1.18-1.88)\end{array}$ \\
\hline
\end{tabular}

\section{DISCUSSION}

Delay in symptomatic presentation for $>3$ months in this group of cancer patients was common. Delay was more common in people of lower socioeconomic status. Strong and common risk factors for delay were prostate cancer, rectal cancer, urinary symptoms, change of bowel habit, rectal bleeding, systemic symptoms, skin symptoms and reporting not having recognised the symptoms as serious.

This survey is unique, as far as we know, in attempting to quantify symptoms and risk factors for delay in presentation in a large population of patients with a range of cancers. The design and reporting were consistent with the Aarhus Statement on early cancer diagnosis research (Weller et al, 2012).

We excluded some common cancers from the analysis, including lung, pancreas, stomach and oesophagus. This was because many of the patients with these cancers had died between diagnosis and the survey. Those who were alive would have been an unusual group; including these would have introduced a greater degree of survivor bias and made our results less generalisable to the whole population of cancer patients. An important limitation of our study is that the conclusions are generalisable to patients with the cancers we have included (who represent about $60 \%$ of cancer patients in the UK) and those who survive for at least a year after diagnosis.

Older people were underrepresented in our study, perhaps because they have worse cancer survival (De Angelis et al, 2014) and are more likely to have died between the Cancer Patient Experience Survey 2010 and our survey. We cannot, therefore, be sure that the findings of no association between age and delay in presentation are reliable. People of non-White ethnic origin were also underrepresented; all patients in our survey were of White ethnic origin. This is at least partly because non-White people were underrepresented in the Cancer Patient Experience Survey 2010 (4\% were of non-White origin (Department of Health, 2010), whereas about $13 \%$ of the adult population of England are of non-White origin (Office for National Statistics, 2013)). We cannot be sure that our findings would apply to patients of non-White ethnic group.

Patients may not be able to recall nature and duration of symptoms, and their reasons for not going to the doctor, accurately and precisely (Jenkins et al, 2002). Recall error may have caused bias in our study if people who delayed presentation were more likely to report reasons for putting off going to the doctor, perhaps seeking to account for their delay. If this was the case, however, we might have expected people who delayed presentation to be more likely to report difficulty in making an appointment as well as, for example, embarrassment or worry about wasting the doctor's time.

We found some evidence that lower socioeconomic position was a risk factor for delay in presentation. The existing evidence on the association between low socioeconomic position and delayed presentation of cancer is conflicting: low socioeconomic position has been found to be a risk factor for delay in presentation of prostate cancer, but not for delay in presentation of colorectal cancer or gynaecological cancer (Macleod et al, 2009). This is important because people of low socioeconomic position have more advanced cancer at diagnosis and worse survival (Rachet et al, 2010; Lyratzopoulos et al, 2012); why this is not clear and it may be at least partly due to longer time to presentation.

Our study has some similar findings to a recently published study documenting GPs' reports of cancer patients' delays in presentation (Keeble et al, 2014). The definition of a 'non-prompt' presentation in that study was duration of symptoms of 15 or more days; overall about half the patients delayed presentation. As in our study, delay was less likely in patients with breast or bladder cancer and more likely in patients with colorectal cancer. However, in contrast, in that study, prostate cancer was not associated with delay, and oropharyngeal cancer was associated with delay. Whether these contrasting results are due to survival bias in our sample or differences in methods of collecting data on duration of symptoms is not clear.

A US study also found, as we did, that patients with prostate cancer were more likely to delay presentation than patients with breast or colorectal cancer (Samet et al, 1988). Most patients with prostate cancer in our study reported urinary difficulties (and vice versa). Urinary difficulties are common in older men with benign prostatic disease (Kupelian et al, 2006). Although urinary symptoms may have led to the investigation and diagnosis of prostate cancer, they may be due to coexisting benign conditions rather than the cancer.

Rectal cancer has been found in previous studies to be associated with longer duration of symptoms than colon cancer (Mitchell et al, 2008). Change in bowel habit, in our study, was almost exclusively reported by bowel cancer patients, and was associated with delay in presentation. Change in bowel habit has been reported to be a risk factor for delay in presentation in another study (Mor et al, 1990) but another found that it was not a risk factor (Pedersen et al, 2013). As with urinary difficulties, change in bowel habit may have an insidious, rather than a dramatic onset, and for short periods of time at least, may be regarded as part of normal variation in bodily functions. Similar issues may explain delay in presentation among patients with skin symptoms, pain and systemic symptoms, particularly fatigue, which is very common in the general population (Pawlikowska et al, 1994; Chou, 2013). Other studies have also suggested that non-specific symptoms are associated with patient delay (Macleod et al, 2009). The evidence relating to pain as a risk factor for patient delay varies by cancer: it is associated with greater delay in urological cancers, but less delay in gastrointestinal cancers (Mitchell et al, 2008; Macleod et al, 2009).

Most patients with rectal cancer reported bleeding, most commonly rectal bleeding, and this was associated with longer 
Table 5. Risk factors for delay in symptomatic presentation: cancer type, symptom and reasons for putting off going to the doctor

\begin{tabular}{|c|c|c|c|c|}
\hline & \multicolumn{2}{|c|}{ Delay in presentation } & \multicolumn{2}{|c|}{ Relative risk for delay in presentation $(95 \% \mathrm{Cl})$} \\
\hline & n & (\%) & Unadjusted & Adjusted $^{a}$ \\
\hline \multicolumn{5}{|l|}{ Cancer } \\
\hline $\begin{array}{l}\text { Prostate } \\
\text { Rectum } \\
\text { Malignant melanoma } \\
\text { Cervix } \\
\text { Uterus } \\
\text { Colon } \\
\text { Chronic myeloid leukaemia } \\
\text { Bone or soft tissue sarcoma } \\
\text { Chronic lymphocytic leukaemia (Reference) } \\
\text { Kidney and ureter } \\
\text { Non-Hodgkins lymphoma } \\
\text { Myeloma } \\
\text { Oral cavity } \\
\text { Bladder } \\
\text { Breast }\end{array}$ & $\begin{array}{c}55 / 115 \\
48 / 131 \\
41 / 142 \\
20 / 76 \\
40 / 139 \\
27 / 108 \\
33 / 137 \\
28 / 127 \\
19 / 94 \\
22 / 123 \\
26 / 150 \\
18 / 119 \\
22 / 147 \\
17 / 144 \\
7 / 83\end{array}$ & $\begin{array}{l}(47.8) \\
(36.6) \\
(28.9) \\
(26.3) \\
(28.8) \\
(25.0) \\
(24.1) \\
(22.0) \\
(20.2) \\
(17.9) \\
(17.3) \\
(15.1) \\
(15.0) \\
(11.8) \\
(8.4)\end{array}$ & $\begin{array}{l}2.37(1.52-3.69) \\
1.81(1.14-2.87) \\
1.43(0.89-2.30) \\
1.30(0.75-2.26) \\
1.42(0.88-2.30) \\
1.24(0.74-2.08) \\
1.19(0.72-1.96) \\
1.09(0.65-1.83) \\
1.00 \\
0.88(0.51-1.54) \\
0.86(0.50-1.46) \\
0.75(0.42-1.34) \\
0.74(0.42-1.29) \\
0.58(0.32-1.06) \\
0.42(0.18-0.94)\end{array}$ & $\begin{array}{l}2.93(1.80-4.79) \\
1.92(1.16-3.16) \\
1.62(0.97-2.70) \\
1.11(0.59-2.12) \\
1.44(0.85-2.46) \\
1.46(0.83-2.54) \\
1.20(0.70-2.07) \\
1.10(0.62-1.93) \\
1.00 \\
1.00(0.58-1.08) \\
0.92(0.52-1.63) \\
0.65(0.34-1.26) \\
0.77(0.43-1.40) \\
0.71(0.37-1.34) \\
0.41(0.18-0.96)\end{array}$ \\
\hline \multicolumn{5}{|c|}{ Presenting symptom. Reference: those who did not report the symptom } \\
\hline $\begin{array}{l}\text { Difficulties with urination } \\
\text { Change of bowel habit } \\
\text { Skin symptoms } \\
\text { Systemic symptoms } \\
\text { Pain } \\
\text { Chest symptoms } \\
\text { Bleeding } \\
\text { Eating-related } \\
\text { Lump or swelling }\end{array}$ & $\begin{array}{c}68 / 167 \\
56 / 146 \\
64 / 207 \\
131 / 460 \\
144 / 551 \\
48 / 189 \\
124 / 524 \\
6 / 28 \\
69 / 411\end{array}$ & $\begin{array}{l}(40.7) \\
(38.4) \\
(30.9) \\
(28.5) \\
(26.1) \\
(25.4) \\
(23.7) \\
(21.4) \\
(16.8)\end{array}$ & $\begin{array}{l}1.91(1.55-2.30) \\
1.77(1.40-2.16) \\
1.40(1.11-1.73) \\
1.34(1.12-1.58) \\
1.20(1.01-1.42) \\
1.11(0.85-1.43) \\
1.04(0.86-1.24) \\
0.93(0.43-1.75) \\
0.68(0.53-0.85)\end{array}$ & $\begin{array}{l}2.12(1.70-2.56) \\
1.82(1.42-2.25) \\
1.42(1.11-1.78) \\
1.33(1.10-1.59) \\
1.19(0.98-1.42) \\
1.08(0.80-1.40) \\
1.03(0.84-1.24) \\
0.91(0.42-1.75) \\
0.61(0.47-0.79)\end{array}$ \\
\hline \multicolumn{5}{|c|}{ Reasons for putting off going to the doctor. Reference: those who did not report the reason } \\
\hline $\begin{array}{l}\text { I was too embarrassed to go to see the doctor } \\
\text { I was too worried about what the doctor might find } \\
\text { I was too busy to make time to go to the doctor } \\
\text { I did not realise the symptom was serious } \\
\text { I was worried about wasting the doctor's time } \\
\text { It was difficult to make appointment with doctor }\end{array}$ & $\begin{array}{c}21 / 31 \\
40 / 70 \\
34 / 69 \\
195 / 512 \\
41 / 109 \\
12 / 46\end{array}$ & $\begin{array}{l}(67.7) \\
(57.1) \\
(49.3) \\
(38.1) \\
(37.6) \\
(26.1)\end{array}$ & $\begin{array}{l}3.04(2.22-3.67) \\
2.63(2.08-3.15) \\
2.24(1.70-2.78) \\
2.21(1.91-2.53) \\
1.70(1.30-2.14) \\
1.14(0.66-1.77)\end{array}$ & $\begin{array}{l}3.07(2.17-3.77) \\
2.62(2.02-3.19) \\
2.31(1.73-2.89) \\
2.24(1.91-2.58) \\
1.54(1.13-2.01) \\
1.18(0.68-1.85)\end{array}$ \\
\hline
\end{tabular}

duration of symptoms, a finding that echoes other studies (Mor et al, 1990; Pedersen et al, 2013). This is surprising, as it is a dramatic symptom, and is likely to be due to pathology. However, we hypothesise that people assume that their bleeding is caused by haemorrhoids, which affect $4-5 \%$ of the adult population (Johanson and Sonnenberg, 1990).

Delay in presentation in breast cancer has fallen over the last 15 years: a systematic review in 1999 patients reported that $18-29 \%$ of breast cancer patients delayed presentation for $>3$ months and reported a decade upon decade fall in the proportion who delayed presentation up until the 1990s (Westcombe et al, 1999); we found that only $8 \%$ of breast cancer patients delayed presentation. There is also evidence for gastrointestinal cancers and urological cancer that patients, over time, are presenting more promptly after onset of symptoms (MacDonald et al, 2004). This may be due to increased awareness of cancer symptoms and confidence to seek help, and broader social changes in the nature of public discourse about health and cancer, including more openness and less stigma.

We did not find strong evidence that worry about wasting the doctor's time or embarrassment can explain the high proportion of people who report delay in presentation. This contrasts with the findings of a 2011 survey of people aged $50+$ in the UK, in which $34 \%$ reported that worry about wasting the doctor's time and $15 \%$ that embarrassment might put them off going to a doctor with a symptom that might be serious (Forbes et al, 2013). What healthy people think would deter them going to the doctor may not be the same as what deters them when they actually experience a symptom.

This study highlights that interventions should ensure that they are designed to work for people from the lowest socioeconomic groups - although our findings suggest that delay in presentation is not uncommon in people from higher socioeconomic groups. Approaches to promoting early presentation should aim to raise awareness of the significance of certain symptoms, in particular rectal bleeding, because there is a high risk of delay in presentation, a high positive predictive value for cancer (Hamilton, 2009) and a low risk of overdiagnosis of indolent tumours (Welch and Black, 2010). Promoting awareness of some of the less-specific symptoms, however, such as urinary difficulties in older men, may expose people to the risk of overdiagnosis of indolent tumours that would never have caused harm, or unnecessary tests and anxiety. Our study can 
contribute to policy on promoting early diagnosis of cancer, and to the government's ambition to improve cancer survival in the UK.

\section{ACKNOWLEDGEMENTS}

Quality Health for carrying out the fieldwork. Department of Health for managing the project. For advice on symptom lists: Mr Bill Allum, Professor Paul Finan, Mr Rob Grimer, Mr Roger Kockelburgh, Mr Martin Lee, Professor Mark McGurk, Professor Julia Newton-Bishop, Mr Andy Nordin, Dr Mick Peake, Dr Hamish Ross. We thank Macmillan Cancer Support and the patients for taking part in the cognitive testing. Examining risk factors for delay in presentation was carried out as part of the programme of the Policy Research Unit in Cancer Awareness, Screening and Early Diagnosis. The Policy Research Unit in Cancer Awareness, Screening and Early Diagnosis receives funding for a research programme from the Department of Health Policy Research Programme. It is a collaboration between researchers from seven institutions (Queen Mary University of London, University College London, King's College London, London School of Hygiene and Tropical Medicine, Hull York Medical School, Durham University and Peninsula Medical School). This work was funded by Policy Research Unit in Cancer Awareness, Screening and Early Diagnosis, National Cancer Action Team/Department of Health, Cancer Research UK.

\section{REFERENCES}

Athey VL, Suckling RJ, Tod AM, Walters SJ, Rogers TK (2011) Early diagnosis of lung cancer: evaluation of a community-based social marketing intervention. Thorax 67: 412-417.

Austoker J, Bankhead C, Forbes LJL, Atkins L, Martin F, Robb KA, Wardle J, Ramirez AJ (2009) Interventions to promote cancer awareness and early presentation: systematic review. Br J Cancer 101: s31-s39.

Burgess C, Ramirez A, Richards MA, Love SB (1998) Who and what influences delayed presentation in breast cancer? Br J Cancer 77: 1343-1348.

Campanelli P (1997) Testing Survey Questions: New Directions in Cognitive Interviewing. Bulletin de Méthodologie Sociologique 55(1): 5-17.

Chou KL (2013) Chronic fatigue and affective disorders in older adults: Evidence from the 2007 British National Psychiatric Morbidity Survey. J Affect Disord 145(3): 331-335.

De Angelis R, Sant M, Coleman MP, Francisci S, Baili P, Pierannunzio D, Trama A, Visser O, Brenner H, Ardanaz E, Bielska-Lasota M, Engholm G, Nennecke A, Siesling S, Berrino F, Capocaccia R (2014) Cancer survival in Europe 1999-2007 by country and age: results of EUROCARE-5-a population-based study. Lancet Oncol 15(1): 23-34.

Department for Communities and Local Government (2014) English Indices of Deprivation 2010, Vol. 2014. http://data.gov.uk/dataset/index-ofmultiple-deprivation. Accessed 22 April 2014.

Department of Health (2010) National cancer patient experience programme: 2010 national survey report. Department of Health. Report no. Gateway reference 14944: London.

Forbes LJL, Linsell L, Atkins L, Burgess C, Tucker L, Omar L, Ramirez AJ (2011) A promoting early presentation intervention increases breast cancer awareness in older women after 2 years: a randomised controlled trial. Br J Cancer 105: 18-21.

Forbes LJL, Simon AE, Warburton F, Boniface D, Brain KE, Dessaix A, Donnelly C, Haynes K, Hvidberg L, Lagerlund M, Lockwood G, Tishelman C, Vedsted P, Vigmostad MN, Ramirez AJ, Wardle J (2013) Differences in cancer awareness and beliefs between Australia, Canada, Denmark, Norway, Sweden and the UK (the International Cancer Benchmarking Partnership): do they contribute to differences in cancer survival? Br J Cancer 108(2): 292-300.
Hamilton W (2009) The CAPER studies: five case-control studies aimed at identifying and quantifying the risk of cancer in symptomatic primary care patients. Br J Cancer 101(S2): S80-S86.

Health and Social Care Information Centre (2014) Demographics systems, Vol. 2014. http://systems.hscic.gov.uk/demographics/index_html. Accessed 23 April 2014.

Jenkins P, Earle-Richardson G, Slingerland DT, May J (2002) Time dependent memory decay. Am J Ind Med 41(2): 98-101.

Johanson JF, Sonnenberg A (1990) The prevalence of hemorrhoids and chronic constipation. Gastroenterology 98(2): 380-386.

Keeble S, Abel GA, Saunders CL, McPhail S, Walter FM, Neal RD, Rubin GP, Lyratzopoulos G (2014) Variation in promptness of presentation among 10,297 patients subsequently diagnosed with one of 18 cancers: Evidence from a national audit of cancer diagnosis in primary care. Inte J Cancer; doi:10.1002/ijc.28763.

Kupelian V, Wei JT, O’Leary MP, Kusek JW, Litman HJ, Link CL, Mckinlay JB. BACH Survey Investigators (2006) Prevalence of lower urinary tract symptoms and effect on quality of life in a racially and ethnically diverse random sample: the Boston Area Community Health (BACH) survey. Arch Intern Med 166(21): 2381-2387.

Lim A, Forbes L, Rosenthal A, Raju K, Ramirez A-J (2013) Measuring the nature and duration of symptoms of cervical cancer in young women: developing an interview-based approach. BMC Women's Health 13(1): 45 .

Lyratzopoulos G, Abel GA, Brown CH, Rous BA, Vernon SA, Roland M, Greenberg DC (2012) Socio-demographic inequalities in stage of cancer diagnosis: evidence from patients with female breast, lung, colon, rectal, prostate, renal, bladder, melanoma, ovarian and endometrial cancer. Ann Oncol 24(3): 843-850.

MacDonald S, Macleod U, Mitchell E, Weller D, Campbell N, Mant D (2004) Factors influencing patient and primary care delay in the diagnosis of cancer: a database of existing research and its implications for future practice. Report no. 1217522. Department of Health.

Macleod U, Mitchell ED, Burgess C, MacDonald S, Ramirez AJ (2009) Risk factors for delayed presentation and referral of symptomatic cancer: evidence for common cancers. Br J Cancer 101: s92-s101.

Mitchell E, Macdonald S, Campbell NC, Weller D, Macleod U (2008) Influences on pre-hospital delay in the diagnosis of colorectal cancer: a systematic review. Br J Cancer 98(1): 60-70.

Mor V, Masterson-Allen S, Goldberg R, Guadagnoli E, Wool MS (1990) Pre-diagnostic symptom recognition and help seeking among cancer patients. J Community Health 15(4): 253-266.

Neal RD (2009) Do diagnostic delays in cancer matter? Br J Cancer 101(Suppl 2): S9-S12.

Office for National Statistics (2011) Cancer Data Tables. http://www.ons. gov.uk/ons/taxonomy/index.html?nscl=Cancer\#tab-data-tables. Accessed 22 February 2012.

Office for National Statistics (2013) 2011 Census, Detailed Characteristics for Local Authorities in England and Wales http://www.ons.gov.uk/ons/ publications/re-reference-tables.html?edition=tcm\%3A77-306085. Accessed 23 April 2014.

Pawlikowska T, Chalder T, Hirsch SR, Wallace P, Wright DJM, Wessely SC (1994) Population based study of fatigue and psychological distress. BMJ 308(6931): 763-766.

Pedersen AF, Hansen RP, Vedsted P (2013) Patient delay in colorectal cancer patients: associations with rectal bleeding and thoughts about cancer. PloS One 8(7): e69700.

Public Health Observatory (2011) Summary IMD 2010 scores for non-LSOA geographies http://www.apho.org.uk/resource/item.aspx?RID=111280. Accessed 23 March 2012.

Rachet B, Ellis L, Maringe C, Chu T, Nur U, Quaresma M, Shah A, Walters S, Woods L, Forman D (2010) Socioeconomic inequalities in cancer survival in England after the NHS cancer plan. Br J Cancer 103(4): 446-453.

Ramirez AJ, Westcombe AM, Burgess CC, Sutton S, Littlejohns P, Richards MA (1999) Factors predicting delayed presentation of symptomatic breast cancer: a systematic review. Lancet 353(9159): 1127-1131.

Richards MA, Westcombe AM, Love SB, Littlejohns P, Ramirez AJ (1999) Influence of delay on survival in patients with breast cancer: a systematic review. Lancet 353(9159): 1119-1126. 
Samet JM, Hunt WC, Lerchen ML, Goodwin JS (1988) Delay in seeking care for cancer symptoms: a population-based study of elderly New Mexicans. J Natl Cancer Inst 80(6): 432-438.

Simon AE, Forbes LJL, Boniface D, Warburton F, Brain KE, Dessaix A, Donnelly M, Haynes K, Hvidberg L, Lagerlund M, Petermann L, Tishelman C, Vedsted P, Vigmostad MN, Wardle J, Ramirez AJ (2012) An international measure of awareness and beliefs about cancer: development and testing of the ABC. BMJ Open 2: e001758.

Stubbings S, Robb KA, Waller J, Ramirez A, Austoker J, Macleod U, Hiom S, Wardle J (2009) Development of a measurement tool to assess public awareness of cancer. BrJ Cancer 101: s13-s17.

Welch HG, Black WC (2010) Overdiagnosis in cancer. J Natl Cancer Inst 102(9): 605-613.

Weller D, Vedsted P, Rubin G, Walter FM, Emery J, Scott S, Campbell C, Andersen RS, Hamilton W, Olesen F, Rose P, Nafees S, van Rijswijk E,
Hiom S, Muth C, Beyer M, Neal RD (2012) The Aarhus statement: improving design and reporting of studies on early cancer diagnosis. Br J Cancer 106: 1262-1267.

Westcombe AM, Richards MA, Ramirez AJ, Love SB, Sutton S, Burgess C, Littlejohns $\mathrm{P}$ (1999) A systematic review of the delay in diagnosis/treatment of symptomatic breast cancer. NHS Cancer Research and Development: London.

This work is published under the standard license to publish agreement. After 12 months the work will become freely available and the license terms will switch to a Creative Commons AttributionNonCommercial-Share Alike 3.0 Unported License.

Supplementary Information accompanies this paper on British Journal of Cancer website (http://www.nature.com/bjc) 